\title{
GÜMRÜ TARIHINDEN SAYFALAR
}

Nazım MUSTAFA *

Rusça'dan Çeviren: Beşir MUSTAFAYEV**

\begin{abstract}
ÖZET
Bu makale, her şeyden önce Gümrü tarihi hakkında gerçeği ortaya çkarmak için şimdiye kadar tarihçilerimiz tarafından ciddi araştırmalar yapılmadığının bir kanıtıdır. Öte yandan Ermeni tarihçileri ise Oguz Yurdu olan bu bolgenin tarihini kendilerine has bir şekilde yorumlamış ve değiştirmişlerdir.

Sơz konusu "Gümrü" kelimesi eski Tưrk dilinde nehir kenarnnda "Tepelik" (yukseklik-tepecik) anlamına gelen cografi bir terimdir. Gerçekten de şehrin eski tepede yerleşen mahallesine Ermeniler 1988 yılına kadar "Türki Mahalle" diyorlardı.

Türk Hükümetinin imzaladığı ilk antlaşma Gümrü'de gerçekleştirilmiştir. İlk siyasi zafer olarak, tarihteki yerini de bőylece almıştır. Antlaşma 18 madde üzerine imzalanmış ve hemen yürürlüge konmuştur.
\end{abstract}

umrü'nün bulunduğu Şirak Vadisi (eski kaynaklarda Sirakhe, Şiragel, 10. S. Șuragel gibi yazılmış. Yerli halk ise Şöreyel ifadesini kullanmıştır.) eski Türk Boylarından Sirak tayfalarının meskeni olmuștur. ${ }^{1}$ Daha sonralar Selçuklular'ın, Karakoyunlu ve Akkoyunlular'ın, Safeviler'in, Çaldıran Savaşından sonra ise Osmanlıları, 1639 senesinde yapılan Osmanl-İran anlaşmasına esasen Gümrü'nün yerleştiği araziler İran'ın tabiligine geçtikten sonra Irevan (Erivan) Hanlığına tabi olan Şöreyel Sultanlığının inzibati-arazi bőlgesine dahil olmuştur.

Nadir Şah'ın zamanında (1746 Türkiye-İran sınır kesiminden sonra.) İzmir etrafindan gelip, Çukur-Sed'de yerleşen Aydın Oguulları Sülalesi Gümrl'de konumlandırnlır. Ve Muhammet oglu Aydın Bey sinır memuru tayin edilir. ${ }^{2} 1802$

\footnotetext{
* Azerbaycan İlimler Akademisi İlmi Araşurmalar Enstitüsu Ögretim Üyesi.

** Sosyal Bilimler Enstitusu Tarih Ana Bilim Dalı.

${ }^{1}$ Kirzıoglu, Fahrettin, Kars Tarihi, s.154, İstanbul, 1953, Bakü 1991.

${ }^{2}$ Guney-Batı Kafkas Hukumeti Geçici Milliyesi, s.207, İst 1986 (Belgeler).
} 
yılının yazında Rus Orduları Pembek dağlarından geçerek ilk kez Şöreyel'e girdiği zaman, Gümru buyưk bir köyü anımsatıyormuş. Kendi mevkiine göre askeri ve stratejik bakımdan önem arz ettiginden, Gümrü tarihen Rus-İan savaşlarının kanlı meydanı olmuştur. ${ }^{3}$

Knyaz Sisianov 12 Haziran 1804 senesinde Gümrü etrafindaki Irevan Kalesini ele geçirmek niyetindeydi. ${ }^{4}$ Sisianov Şöreyel Sultanlığı'nın Rusya'ya birleştirilmesi yönünde belgeyi aksettiren raporunda, Gümrü'nün Muhtarı Cafer Bey, Rusya'nın tabiiliģine geçtiğinden, imparatora sadık kalmak için, 31 Ocak 1805 yılında oglunu Karakilise'ye Rus Ordularının Kumandanı General Nesvetayev'e gơndermiş ve haber vererek, onun orduları engel olmadan Gưmrü'den geçerek Şöreyel'in merkezi olan Ertiy'i alabilirler.'

30 Mart 1805 senesinde Rus Orduları Ertiy'i işgal ederek, 20 Ekim tarihinde Şöreyel'in ebedi olarak Rusya'nın himayesine geçmesi konusunda 7 maddelik karar imzalıyorlar. ${ }^{6}$ Rusların Şઠreyel'i işgalinden sonra İrevan Hanlığını tehdit etmesi ve Osmanlı-İran arasındaki anlaşmazlık sorun oluşturuyordu. 1807 senesinin ilkbahar aylarında Erzurum Serkerdesi Yusuf Paşa, Nesvetayev'e mektup göndererek ateşkes yoluyla Gürri'yü teslim etsin. Mayıs'ın 19'da Yusuf Paşa 7000 kişilik orduyla Arpaçay'ı geçerek Gümrü'ye hücum ediyor. Bu durumda Ruslar geri çekilmek zorunda kalıyor. Gümrü'nün sokakları kanlı savaşlara sahne oluyor. Yusuf Paşa Nesvetyev'den bulunduğu yerden çıkmasını talep ederek, savaşmak için er meydanına davet ediyor. Diger yandan zaman kazanan Nesvetayev ona yardıma gelen graf Gudoviç'in orduları ile birleşerek hücuma geçiyor. Neticede Türk Orduları ağır kayıplar vererek geri çekilmeye mecbur oluyor.?

GeneraI Nesvetayev graf Gudoviç'e 29 Ekim 1807 yllında yazdığı raporunda şöyle diyordu: "Gümrü'nün sahibi Cafer Bey'in çocukları Kerim Bey ve Hüseyin Bey İrevan'a Hüseyin Gulu Han'ın yanına sığınmışlar."8 Genellikle Rus Ordularının Şorreyel'i işgal anından sonra aynı arazide yașayan Karapapak tayfalarının Kars Paşalığı ve İrevan Hanlığının arazilerine goç etmişlerdir. Aynı zamanda İrevan Hanlığının arazisinden Ưçkilise'den (Ecmiedzin'den) kaçan Ermeniler, Ruslar'ın himayesi altında, Pembek ve Şöreyel'de barındırılır.' Böylece bölgenin muslüman ahalisinin sayısı azaltıllyordu.

\footnotetext{
${ }^{3}$ Kafkazskiy Kalendar na 1851, c.3, s.104, Tiflis 1850.

${ }^{4}$ Aktı Sobiranie Kafkazskoy Arkeologiceskoy Komissiey, c.2, s.615, Tiflis 1868.

${ }^{5}$ Akt, c.2, s.672.

s.g.e, s.577-578.

${ }^{7}$ Gümrli Makalesi, Voennaya Ansiklopediya, s.534, Petersburg 1912

8 a.g.m, c. 3, s. 240

${ }^{9}$ a.g.m, s.537
} 
21 Temmuz 1809 yılında Gümri etrafinda Rus Orduları ile Abbas Mirze'nin orduları arasında şiddetli çatıșmalar devam ediyordu. Ruslar bu çatışmada üstünlük elde ederek kendi mevzilerini güçlendiriyorlar. ${ }^{10}$

16 Haziran 1826 yılında İrevan Han'ın kardeşi Hasan Han'ın orduları Gümrü'yü kurtarmak için yeniden hücuma geçiyor. Ama o isteğine kavuşamıyor. Ruslar başlıca mevzilerini Gümrü'de toplayarak İrevan uzerine hücuma hazırlaniyorlar.

Öte yandan Ermeniler, Rus Ordusu ile birlikte Gümrü'ye gelerek kısmen de olsa bölgeye yerleşiyorlar. 1826-1828 Rusya -İran, 1828-1829 Rusya-Türkiye savaşlarından sonra (Türkmençay ve Edirne anlaşmalarına göre) Doğu Anadolu'da yaşayan Ermenilere, Rusya'nın Kafkasya'da işgal ettiği arazilere (Karabağ ve İrevan bölgeleri esas olmak üzere) göç etmelerine izin verilmiştir. Sadece 1828-1829 senelerinde Gümrü ve Talın'a 2500 aileden oluşan Kars Ermenileri yerleşmişlerdir. ${ }^{11}$

Savaştan sonra bölgede yerleşen Türk kðylülerinin ahalisi yaylaya çıtıktan sonra, evleri ve eşyaları Ermeniler tarafindan tâlan edilmiştir. Degerli eşyaları Türklerin elinden alınarak Ermeni göçmenlerine verilmiş ve Türkleri hayvan barınaklarında yaşamaya zorlamışlardır. Tüm bu olaylardan sonra bollgenin mevcut Türk ahalisi toplu şekilde göçe zorlanmışlardır. Ermeni tarihçileri Gümrìnuủn ahalisi hakkında istatistigi bilgileri sadece 1831 senesinden itibaren ele almaktalar. Çünkü o zamana kadar Turkiye'den göç eden Ermeniler'in sayesinde, Gümrü'nün nufuzu sayıca Ermeniler'in üstünlügü ile sonuçlanmıștı. Ama Kafkasya Canişiliği'nin arşiv belgelerinde Rus Ordularının Ş̋rreyel'e girdiği zaman bölgede bir Ermeni dahi yaşadığına dair bilgi verilmiyor. Kısaca bu zamana kadar bölgede hiçbir Ermeni yaşamamış, aksine Türkler'in bölgedeki varlığından ve ağırlığından bahsediliyor.

1837 senesinde İmparator 1.Nikolay'ın katılımı ile Gumru'de askeri yerleşim merkezinin temeli atıliyor ve bu merkeze İmparatoriçenin onuruna Aleksandropol adı veriliyor. ${ }^{12} 1840$ yılında Aleksandropol kazası oluşturulur ve Gürcủ Guberniyası'nın terkibine devredilir. Daha sonra 1844 yılında Kafkas Canișiliginin yeni inzibati bőlgesine esasen Aleksandropol ve İrevan Kazaları Tiflis Guberniyasına devrediliyor. 1849 yılında İrevan Guberniyası olușturulduğu zaman Aleksandropol Kazası bu Guberniyanın terkibine dahil edilir. Aleksandropol Kazasının terkibinde 4 mıntıka - Akbulak (49 köyden oluşuyor), Cızıklar (43 köy),

\footnotetext{
${ }^{10}$ a.g.m, c.4, s.690.

${ }^{11}$ B.Parsamyan, İstoriya Armyanskogo Naroda, s.66, Ermenistan 1972.

${ }^{12}$ Kafkazskiy Kalendar na 1851 goda, c.3, s.105, Tiflis 1850.
} 
Horom (38 köy) ve Büyuk Karand olmuştur. ${ }^{13}$

Aleksandrupol resmi şehir statüsünü 1850 senesinde almıştır. $\mathrm{Bu}$ andan itibaren 1920 yılına kadar gibi bir surede şehrin ahalisi İrevan Şehrinin ahalisinden fazla olmuştur.

Ermeni tarihçisi B. Parsamyan'ın araştırmalarında, 1831 senesinde Gumru'de 3444 kişi yaşadığını belirtiyor. Bunların 3194 Ermeni, 250'si ise diger azınlıklar olduğunu iddia ediyor. ${ }^{14}$ Öte yandan o, Gümru'nün eski Türk bölgesi olduğunu inkâr ederek, başka bir eserinde Ermeni riyakârlığı ile ilgili şöyle yazıyor: "Bu devirde (yani 1850 yılını kastederek) Aleksandropol'un nüfusu 11280 kişiye ulaşmıştı ve tüm nüusu Ermeniler'den oluşan yegane Ermenistan Şehri idi. ${ }^{15}$ Diğer yandan Kafkas Kalendarının (takvim) 1951 yılı basımında şehrin nüfusu konusunda şőyle bilgi verilmekte: Ermeniler-10696, Müslümanlar-410, Yunanlllar-165, Ruslar ise 165 , toplam $11280 .^{16}$ Aynı zamanda şehirde 7 kervansaray, 45 dukkan, 16 kahvehanenin de mevcut oldugu bildirilmekte."17

Gümrü ve onun civar köylerinde Türkiye'den göç eden Ermeniler toplu şekilde yerleştiłgi için bu bölgenin 100'e yakın köyün Türk ahalisi göçe zorlanmıştır. Nüfusun, 1873 y1lının bilgilerine gơre Şöreyel'de 9 karışık Türk köyü mevcut idi. ${ }^{18}$ Gümrü'nün Türk ahalisi zengin tacirlerden olușuyordu. Onlann aracılığıyla da İran ve Türkiye arasında ticari ilişkiler yürütülüyordu. Bölge 1843 yılında Kafkasya'da gelir dağılımına göre 8. sıradaydı. 1845 senesinden itibaren her yıl şehirde iki hafta süreyle ticaret fuarları düzenleniyordu. ${ }^{19}$

1886 yılında Kafkasya'da yapılan genel sayımın sonuçlarına göre, Aleksandropol Kazasında 16905 aile, 13573 kişiden 680 aile ve 5461 kişi Türk idi. Gümru'de ise toplam 89 aile 881 kişi Türk yaşadığ yơnünde bilgi verilmektedir. ${ }^{20}$

1 Ocak 1905 tarihine kadar Aleksandropol kazasında müslumanların sayısı

13 Svod Statikticeskih Dannih o Naseleniya Zakavkazskogo Kraya, Izvlesennıh Iz Posemeynih 1886 goda, Tiflis 1893.

${ }^{14}$ B.Parsamyan, Hay Azadagragan Şarjumneri Badmutyunis.

${ }^{15}$ B.Parsamyan, İstoriya Armyanskogo Naroda, s.98, Ermenistsn 1972.

${ }^{16}$ Kafkazsiy Kalendar, Na 1852 goda, s.277, Tiflis 1851.

${ }^{17}$ a.g.m, s.280.

18 Materiali Dlya İzueceniya Ekonomiceskogo Bita Gosudarstvennıh Krestyan Za Kafkazskogo Kraya, Tom.1, Vınusk 1, s.5, Tiflis 1885.

${ }^{19}$ B.Parsamyan, Hay Azadagragan Şarjumneri Badmutyanis, s.89.

${ }^{20}$ Svod Statitiçeskih Dannıh o Naselenii Zakavkazskogo Kraya, İzvlecennıh İz Posemeynıh Spiskov 1886 goda, $\mathbf{5 . 3 2 8}$, Tiflis 1893 . 
9837, Gümrü'de ise 1572 kişi olmuștur. ${ }^{21}$ Rusya'da, Kasım 1917 devriminden sonra Rus Orduları 40 yıl önce işgal ettikleri Kars Vilayeti'nden geri çekilmek zorunda kaldıkları için, Ermeniler Ruslar'ın bıraktığı silahları ele geçirerek, Kars ve civar kőylerinde, Gümrü ve civar köylerinde yașayan müslüman Türk milletini vahşice katletmişlerdir. 29 Nisan 1918 senesinde Gümrü'den Ahılkelek yolu ile arabalarla Gurcistan'a, oradan da Azerbaycan'a gitmek isteyen 3000'e yakın Turk insanını, kadın, yaşlı ve çocuk demeden yollarda hunharca katletmişlerdir. ${ }^{22}$

Türk Orduları Erzurum ve Kars'ı Ermeni zulmünden kurtarmak için 15 Mayıs tarihinde Gumru'ye hücum ediyorlar. Şehre girmeden önce Kâzım Karabekir Paşa Gümrü'de Ermeni hulkumetine: "Şehirdeki mevcut Türk ahaliye köpru başına gelerek teslim edin."diyerek mektup gönderir. Bunun üzerine telaşa kaplan Ermeniler, Gümrü'de bulunan 250 haneden oluşan Türkleri arabalara bindirerek, Arpaçay Köprüslinden geçerek Turk Ordularına teslim ediyorlar. ${ }^{23}$ Bu olayla ilgili Kâzım Karabekir Paşa şoyle yazıyor: "Gümrủ kobylerinde çok az sayıda yaşlı kadın ve erkek kalmıştı. Gümrü'de 8-10 Türk evi vardı. Orada Türk gençleri ise yoktu. Yaşlı Türk anne ve babalar askerlerimize sarılarak öpüyorlar." Elinde kanlı bir asa, aksakallı ve bir çok yerlerinden kanlar akan, fakat dimdik ayakta duran bir baba askerimizin boynuna sarılarak şoyle haykırıyor: "1878 savaşından beri bir gün dahi ümidimizi yitirmeden, size kavuşacağımızı biliyorduk. Fakat, artık dünyanın sonuna kadar dahi ayrılmayacağız.” Ve gözlerinden yaşlar akıyordu.

Yaralı, ak saçlı ve kanla ıslanmış saçları sanki başına bir Türk bayrağı sarılmış görünümünú veren ihtiyar kadın, diğer bir askerimize sarılarak şboyle haykırıyordu: "Oğlum, bizi bu duruma Ermeniler getirdi. Fakat çok şükür ki, bir daha gelmeyecekler. Oğlum, Karabekir Paşa nerededir? Ben ona sarılmadan ölmek istemiyorum." Ve beni gördügü anda bayılıyor. Dizlerime sarılıp, göz yaşları, hıçkırıklan ile şükranlarını ifade etmeye çalışıyor ve dualar ediyordu. ${ }^{24}$

Kâzım Karabekir Paşa askeri mevzilerini, Ruslardan kalan askeri üslerde konumlandırdıktan sonra, şehirde asayişi ve düzeni yeniliyor. Böylece şehrin eski Turk yerlileri kendi evlerine ve yurtlarına geri dönmeye başlıyorlar.

26 Mayıs 1918 senesinde Kafkasya Seymi bırakıldıktan sonra Gurcistan, Azerbaycan ve Ermenistan bağımsızlıklarını ilân ediyorlar. 4 Haziran'da Batum'da Türkiye ile barış ve dostluk anlaşması imzalanıyor. Kars Vilayeti'nin arazisi tümüyle Aleksandropol Kazasının dörtte üçü ve Kars-Aleksandropol-Culfa

\footnotetext{
${ }^{21}$ Kavkazskiy Kalendar na 1907 goda, s.328, Tiflis 1906.

${ }^{22}$ Kars Şehitlikleri ve Mehmetçiğimiz, s.73-315, Ankara 1986.

${ }^{23}$ Fahrettin Erdoğan, Türk Ellerinde Hatıralarım, s.155, İst 1954.

${ }^{24}$ Kâzım Karabekir'in Kaleminden, Doğunun Kurtuluşu, s.371, Erzurum 1990.
} 
(Nahçıvan'da bir şehir) demiryolu hattı Türkiye'nin kontrolüne geçiyor. ${ }^{25}$

Doğu Anadolu cephesi 9.Ordu Komutanı Yakup Şevki Paşa, Gümrla'lü Cihangir Oglu İbrahim Bey'i (Rus arşivlerinde soyadı Cahingirov olarak kaydedilmiştir) Doğu Şorreyel'e kaymakam tayin ediyor. ${ }^{26} \mathrm{O}$, Türk bayrağı altında yerleşen İrevan ve Gümrü göçmenlerine her türlu yardımı yapıyor. ${ }^{27}$ Sonralar İbrahim Bey Kars'ta kurulan Cenubi -Garbi Kafkas Hüklumetinin başkanı seçiliyor.

1.Dünya Savaşında Türkiye'nin yenilgisinden sonra, 30 Ekim 1918 senesinde Mondros Anlaşmasına esasen Türk Orduları kendi sınırlarına geri çekilmek zorunda kaldığından Gümrü'nün müsluman ahalisinin kötü günleri yeniden başlıyor. Aynı yılda çıkan "Gruziya" (Gürcistan) Gazetesi şbyle yazıyordu: "Aleksandropol'da Ermeni güçleri artileriyadan müslüman hanelerine ateş açarak, kendi silahlarını ve güç oranlarını kontrol ediyorlardı."28

Şahitlerin sőylediklerine göre,Türk Orduları geri çekildikten sonra Gümru'nün müslüman ahalisinin tehlikesiz bir şekilde göç etmesine Muhammet Ağa Akbaba Nahiyesinin arazisinde yegane Ermeni koyu Karamemmed Koyuunuln Ermenileri'ni (1879 senesi göç tazminatından sonra burada yaşamışlardır.) sakladılar. Gümrlilüler'in ev eşyalarını taşımak için civar köylerden 100'e yakın araba ayarladilar.

Akşamdan hazırlanan arabalar sabahın erken saatlerinde Hacı Usub Oglu Hümbet Ağa sinirlenerek şöyle diyordu: "Kırın, kırın, di sizin mezhebinizi.... Bu mu sizin erkekliğiniz? Silahsız insanları, çocuk, kadın ve yaşlıları öldürmek erkeklik değil.

O dehşetli kıyımın ardından civar köylerden seferber edilen birkaç arabacıyla, insanlar Arpaçay üzerindeki kðprüyul geçerek, Türk toprağı olan Molla Musa Köyüne ulaşabildiler.

Gümru'de yapılacak soykırımm haberi onceden Karamemmed Koyünün Ermenileri'ne bildirildiģi için, onlar o gece derenin içi ile yürüyerek, Gümrü'ye kaçmışlar. Gümrülü gőçmenler önceden Kars Vilayeti'nin köylerine yerleşmişlerdi. Kasım 1918 senesinde Kars'ta milli şûra kuruluyor. Sonra ise milli şûranın karan ile Batum'dan Nahçıvan'a kadar olan araziyi birleştiren Güney-Batı Kafkas Cumhuriyeti kuruluyor. 13 Nisan 1919 yılında İngilizler bu hukkumeti alarak

${ }^{25}$ Zavriev, D.S. k Noveyşey İstorii Çevero-Vostocnıh Vilayetov Turcii, s.71, Tblisi (Tiflis) 1947.

${ }^{26}$ Azerbaycan Respublikası M.D.Y.T.A, F.970, siyahı 1, İş 27.

${ }^{27}$ Cenubi-Garbi Kafkas Hükümeti Mufakkati Milliesi, Belgeler,Fotoğraflar, s.211, Ankara 1986.

${ }^{28}$ Gruziya Gazetesi, 28 Kasim 1918. 
Ermenilere teslim ediyorlar. ${ }^{29}$ Gümrü Kazası'nın göçmen Türkleri, Ermeni Ordularının işgal edemediği Ağbaba ve Zerşad bölgelerine sığınıyorlar. Binlerce aç ve susuz gðçmenlerden her gün 40-50 kişi çeşitli hastalıklardan ölmüştür.

Nisan 1920 senesinde Gümrü demiryolu istasyonunda Ermeniler bir kez daha soykurım gerçekleştiriyorlar. Azerbaycan'a ve başka yerlere gitmek üzere İrevan'daki Azerbaycan Elçisinin verdiği pasaportları taşıyan, İrevan civarından trenle Gence'ye giden 500 Türk Gümrü yakınlarında vahşice katletmişlerdir. ${ }^{30}$

Gümri ve etraf bollgelerinde baş veren soykırımlar 1920 yılının ilkbaharına kadar devam etmiştir. Bölgenin Müslüman ahalisini Ermeni zulmünden Türk Ordusu kurtariyor. Türkler Ekim ayının 29'da Kars'1 kurtardıktan sonra Kâzım Karabekir Paşanın kumandanlığı altında 7 Kasım tarihinde Gümrü'yü kurtararak, İrevan uzerine hücum ediyor.

28 Nisan 1920 yılında Bakl'de Bolşevik devriminden sonra Azerbaycan Ordusunun Karabağ süvari alayı Hüdaverin Köprüsünden geçerek, İran arazisinden Türkiye'ye geçiyor. Bu alay 12. divizyanın emrine verilmiş, Kars'1 kurtarma operasyonunda 9. piyade tugayının terkibine geçmişti. Azerbaycan askeri birlikleri Türk Ordularının Ermenistan seferinde de yer almıştır.

Gümrü ve Cacur savaşından sonra İrevan'a yönelen boblukler Ermenilerin barış istemelerine göre Düzkent Köyüne geri çekilme emri almış ve burada ihtiyati güç olarak bekletiliyordu. ${ }^{31}$

Tük Orduları karşısında yenik düşen Taşnak (Terör Örgütu) Hükümeti 18 Kasım'da barış istemiş ve anlaşmaya göre Arpaçay Nehrinden $15 \mathrm{~km}$ doğuya çekilmeye mecbur olmuştur.

2-3 Aralık tarihlerinde iki taraf arasında Gümri Barış Anlaşması imzalanmıştı. ${ }^{32}$ Anlaşmaya göre Ermenistan şimdiki arazinin uçte iki hissesini kaybetmekle, 1500 askerden, 8 sahra topu ve 8 uçaksavardan fazla ordu barındırma yetkisinden mahrum ediliyordu.

29 Kasim 1920 senesinde Ermenistan'da Sovyet Hakimiyetinden sonra Gümrï anlaşması geçersiz ilân ediliyor. Rusya'nın tekidi ile Tưrk birlikleri

\footnotetext{
${ }^{29}$ Azerbaycan Respublikası M.D.Y.T.A, F.897, Sayı 1, İș 64, s.2.

${ }^{30}$ Kars Şehitlikleri ve Mehmetçigimiz, Hazırlayan C. Aslanoglu, s.329, Ankara 1987.

31 Hüseyin Baykara, "1.Dünya Savaşında,Osmanlı Ordusunda,İstiklâl Savaşında Türkiye Ordusunda Azerbaycan Askeri Kıtaları." Makalesi, Türk Kültür Dergisi, s.72-74, İst 1964.

${ }^{32}$ Türk Ansiklopedisi, c. 18, "İstiklâl Harbi", s. 156-157.
} 
Gümrï'yư terk ederek, Arpaçay Nehri'nin doğusuna çekilmek zorunda kalmıştır. ${ }^{33}$

1920 senesinden sonra Gümrü'de Ermeniler ile akraba olarak kaynaşma içerisinde olan sadece bir Türk ailesinden başka kimse yaşamıyordu. 1924 senesinde Gümrü Kentine Leninakân adı veriliyor. 1988 Ermenistan depreminden sonra kent, şimdiki yerinden batıya dogru yeniden inşa edilerek ve ismini de Gümrü'ye benzer Gümayri adı verilmiştir.

Ama tüm tarihi kaynaklarda kentin eski adı Güınrü gibi yazıldığından Ermeniler 1992 senesinde kentin eski adını yeniden koymak zorunda kalmıştır. ${ }^{34}$

\begin{abstract}
This article, first of all, is a proof that serious researches weren't dealt with history of Gumrü to reveal the truths by our historians up to now.

The Armenian Historians, on the other hand, commented and changed its history of this area that belongs to Oguz Country without researching.

The above-mentioned word "Gumrü" is geographical term which means "Hillock (Height) near the river" in ancient Turkish Language.

The Armenian really called "Turkish Quarter" since they settled down the old hill of the city up to 1988 .

First Agreement that is signed by Turkish Government happened at "Gümrü". Thus, It made history as the first political victory.

Finally, this 18 -entries agreement is brought into force at once.

${ }^{33}$ V.Gurko-Kryajin, Ermeni Meselesi, s. 17, Bakü 1990; Voennaya Ansiklopedya, s.261, Bakü
\end{abstract} 1976.

${ }^{34}$ A. Bayramov, "Gümrü", hlim ve Hayat Dergisi, Bakù 1990. 


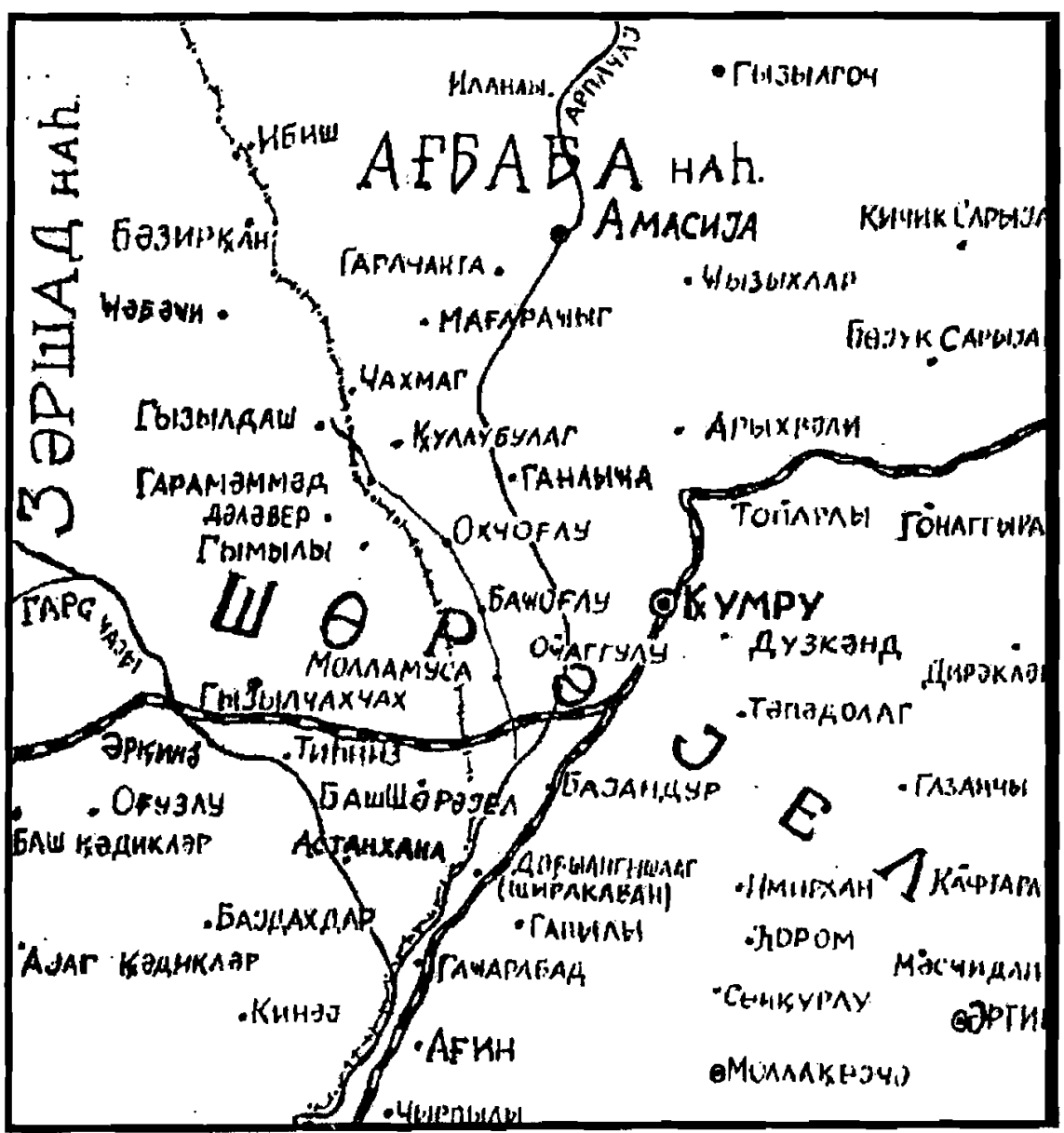


.

$$
\text { . }
$$

